\title{
A COMPARATIVE EVALUATION OF FLUORIDE RELEASE, RECHARGE AND RE- RELEASING ABILITIES OF THREE DIFFERENT RESTORATIVE MATERIALS - AN INVITRO STUDY
}

\section{Sunil Kumar}

\section{Obula Reddy*}

\section{S. Datta Prasad}

\section{N. Vamsee Krishna}

\section{S. Sunil Kumar}

MDS Professor Department Of Conservative Dentistry And Endodontics, CKS Theja Institute Of Dental Sciences And Research, Tirupati517501,Chittoor District, Andhra Pradesh, India.

Post Graduate Student Department Of Conservative Dentistry And Endodontics, CKS Theja Institute Of Dental Sciences And Research, Tirupati517501,Chittoor District, Andhra Pradesh, India. * Corresponding Author

MDS, Head Of Department Of Conservative Dentistry And Endodontics, CKS Theja Institute Of Dental Sciences And Research, Tirupati-517501,Chittoor District, Andhra Pradesh, India.

MDS, Reader Department Of Conservative Dentistry And Endodontics, CKS Theja Institute Of Dental Sciences And Research, Tirupati-517501,chittoor District, Andhra Pradesh, India.

MDS, Reader Department Of Conservative Dentistry And Endodontics, CKS Theja Institute Of Dental Sciences And Research, Tirupati-517501,Chittoor District, Andhra Pradesh, India.

MDS, Reader Department Of Conservative Dentistry And Endodontics, CKS Theja Institute Of Dental Sciences And Research, Tirupati-517501,Chittoor District, Andhra Pradesh, India.

ABSTRACT INTRODUCTION: The most important property of Fluoride is anti-cariogenic property which aids in remineralization of incipient carious lesions in enamel thereby inhibiting enamel demineralization i.e. it helps in arresting or reversal of incipient enamel lesions. A prolonged exposure of incipient carious lesions to fluoride in the aqueous phase achieves the cariostatic effect.

OBJECTIVES: The aim of the present study is to evaluate the amount of fluoride released by three different Restorative Materialsi.e. Glass Ionomer Cement, Resin Modified Glass Ionomer Cement, Cention on 1st,7th and 15th day followed by Recharge and Re-release after recharging with various Flouride applications.

MATERIALS AND METHODOLOGY: Fifteen Disk-shaped specimens for each group ( $8.5 \mathrm{~mm}$ diameter; 3 mm thickness) were prepared from three different restorative materials using cylindrical Teflon molds according to manufacturer's instructions. The specimens in each individual group were incubated in a $95 \%$ relative humid environment at $37^{\circ} \mathrm{C}$ for 24 hours. Specimens of each group were immersed in $20 \mathrm{ml}$ deionized water in plastic bottles and stored in the incubator at $37^{\circ} \mathrm{C}$, Fluoride concentration was measured using a UV Spectrophotometer after 1 st , 7th \& 15 days.

The samples from each group were now divided into: 3 Sub Groups of five each. Sub Group A - Control group - No topical fluoride application. Sub Group B - The samples were recharged with 2\% Neutral Sodium Fluoride solution for 4 minutes and washed with copious deionized water for $10 \mathrm{sec}$ and dried on absorbent paper. Sub Group C - The samples were recharged by hand brushing with a Fluoridated brushing Dentifrice for four minutes and then wiped clean with a tissue and rinsed for 10 sec using copious deionized water and dried. Measurement of fluoride Re-release is done by UV Spectrophotometer after lst ,7th and 15thday after recharge.The results were statistically analysed using analysis of variance (one-way ANOVA) and Tukey Kramer multiple comparison tests $(\mathrm{p} \leq 0.05)$.

RESULTS: Independent of the observation time period of thestudy the Conventional GIC released the highest amount of fluoride followed by RMGIC \& CENTION. The initial burst effect was seen with GIC'S but not with RMGIC, CENTION. After topical fluoride application fluoride re-release was highest in Sub Group B and GIC had a greater recharging ability followed by RMGIC \& CENTION. The fluoride re-release was greatest on lst day followed by rapid return tonear exposure levels. CONCLUSION: From the study it was concluded that, the initialFluoride release was highest from Conventional GIC followedby Resin Modified GIC, CENTION. The Fluoride release was high when recharging with professional regime ( $2 \% \mathrm{NaF}$ ) as compared to home regime (Toothpaste).

\section{KEYWORDS : Fluorides, Fluoride Uptake, Fluoridated Dentrifices, Fluoride Releasing Materials.}

\section{INTRODUCTION}

The most important property of fluoride its anti-cariogenicity, apart from its above aids in remineralization of incipient carious lesions in enamel thereby inhibiting enamel demineralization i.e. it helps in arresting or reversal of incipient enamel lesions. A prolonged exposure of incipient carious lesions to fluoride in the aqueous phase achieves the cariostatic effect. ${ }^{15}$

Amongst the fluoride-releasing restorative materials, conve ntional glass Ionomer cements (GICs) (FUIII IX GP) emerge on top because of their efficacy in resisting secondary caries formation around restorations. However, they are poor in compressive strength and translucency in comparison to composite resins.

To overcome the shortcomings of Conventional GICs, while maintaining their clinical advantage in caries inhibition, hybrid materials that purportedly combine the benefits of glass ionomers and composite resins were developed, eg: 
Resin-modified Glass Ionomer cements (RMGICs) and based on fluoride release and recharge mechanisms, GICs and composites have shown to be able to release, absorb, and rerelease fluoride. These fluoride-releasing restorative materials act as a fluoride reservoir to maintain increased levels of fluorine around restorations to prevent or inhibit secondary caries formation.

CENTION-The new filling material that belongs to the materials group of Alkasites that offers tooth-colored esthetics together with high flexural strength. This patented alkaline filler increases the release of hydroxide ions to regulate the $\mathrm{pH}$ value during acid attacks. As a result, demineralization can be prevented. Large numbers of fluoride and calcium ions release forms a sound basis for the remineralization of dental enamel. High flexural strength occurs due to highly crosslinked polymer structure. The initiator system enables good chemical self-curing as well as light curing property thus enabling dual cure property. The liquid comprises methacrylate's and initiators, whilst the powder contains various glass fillers, initiators and pigments. UDMA is the main component of the monomer matrix. It exhibits moderate viscosity and yields strong mechanical properties ${ }^{16}$

Hence aim of the present study is to evaluate the amount of fluoride released by three different Restorative Materials i.e. Glass Ionomer Cement, Resin Modified Glass Ionomer Cement, Cention on 1st,7th and 15th day followed by Recharge and Re-release after recharging with various Flouride applications.

\section{METHODS AND METHODOLOGY: -}

\section{A) MATERIALS:}

1. Conventional Glass Ionomer Cement (FUJII IX GP)

2. Resin Modified Glass Ionomer Cement (KETAC N100)

3. CENTION N (IVOCLAR)

4. Agate spatula

5. Mixing pad

6. Cylindrical Teflon Molds

7. Polyester Strips

8. Glass Slide

9. Sterile container

10. $2 \%$ Neutral Sodium Fluoride solution

11. Fluoridated dentifrice

\section{B) METHODOLOGY}

\section{PREPARATION OF THE SPECIMEN: -}

45 Disk-shaped specimens were selected and divided into three groups $(\mathrm{n}=15)$ for each group $(8.5 \mathrm{~mm}$ diameter; $3 \mathrm{~mm}$ thickness) were prepared from three different restorative materials using cylindrical Teflon molds according to manufacturer's instructions. Polyester strips were then placed on the top and bottom surfaces of each mold with glass slides placed over the polyester strips to produce a smooth surface. Excess extruded material was carefully removed using a surgical blade.

The specimens were prepared according to manufacturer's Instructions. Immediately after mixing, the cement was inserted into the mold and its top and bottom surface was covered by a polyester strip and was allowed to set in the mold for a total of 7 minutes. Specimen were light-cured for $20 \mathrm{~s}$ from each surface of the mold.

\section{FLUORIDE RELEASE: -}

The specimen in each individual group were incubated in $95 \%$ relative humid environment at $37^{\circ} \mathrm{C}$ for 24 hours. specimen of each group was immersed in $20 \mathrm{ml}$ deionized water in plastic bottles and stored in the incubator at $37^{\circ} \mathrm{C}$. Fluoride concentration was measured using UV Spectrophotometer, where the detection limit was $\pm 0.001 \mathrm{ppm}$ and all data was recorded in ppm.
After 24 hours, the containers were vigorously shaken and the samples were removed, dried and returned into a new vial containing $20 \mathrm{ml}$ of deionized water. The cumulative fluoride release measurement was made by an ion-selective electrode (ISE) attached to an ion meter after lst day, 7th day and 15th day.

- After 15 days the samples from each group were divided into: 3 Sub Groups of six each. Sub Group A - Control group - No topical fluoride application. Sub Group B - The samples were exposed to $2 \%$ neutral sodium fluoride solution for 4 minutes and washed with copious deionized water for $10 \mathrm{sec}$ and dried on absorbent paper. Sub Group C - The samples were hand brushed with a fluoridated dentifrice for four minutes and then wiped clean with a tissue and rinsed for $10 \mathrm{sec}$ using copious deionized water and dried. Each sample after fluoride application was suspended in plastic bottles containing $20 \mathrm{ml}$ of deionized water and incubated at $37^{\circ} \mathrm{C}$ for 24 hours

- After 24 hours samples were removed from the bottle, washed with $1 \mathrm{ml}$ of distilled water using a syringe, dried on absorbent paper and then restored in $20 \mathrm{ml}$ of fresh deionized water. Measurement of fluoride Rerelease is done by UV Spectrophotometer (fig 1) after lst, 7th and 15thday.

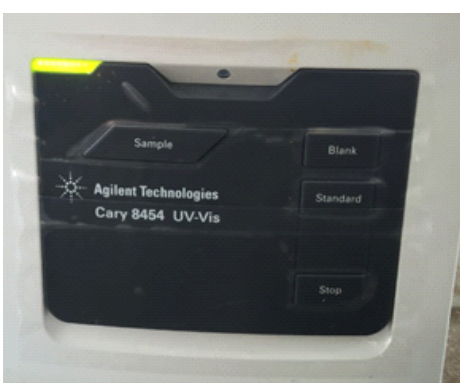

\section{FIGURE - 1}

\section{STATISTICAL ANALYSIS: -}

Statistical analysis was performed using Analysis of Variance (ANOVA) for multiple groups and Tukeys multiple post hoc procedure (T HSD) for pair wise comparison of two groups.

\section{RESULTS:}

Analysis of data revealed that there was significant difference in fluoride release on different days and different materials and also in fluoride re-release before and after recharge between different days and materials $(p<0.05)$ using GIC, RMGIC AND CENTION as shown in tables 1,2 and 3 respectively.

\section{TABLE- 1}

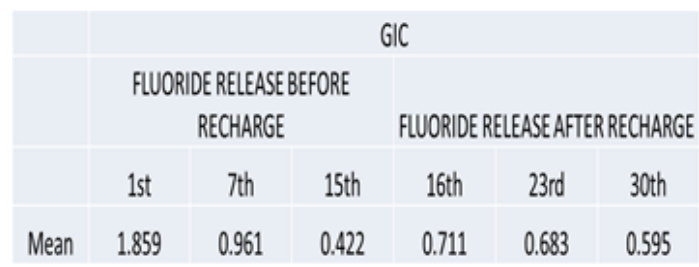

TABLE -2

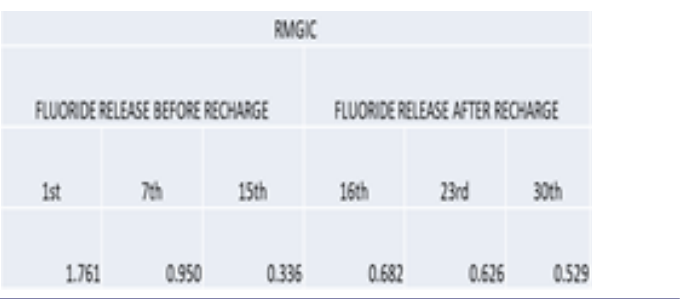


TABLE -3

\begin{tabular}{|c|c|c|c|c|c|}
\hline \multicolumn{4}{|c|}{ Cention } \\
\hline \multicolumn{3}{|c|}{$\begin{array}{c}\text { Fluoride Release Before } \\
\text { Recharge }\end{array}$} & \multicolumn{3}{|c|}{$\begin{array}{c}\text { Fluoride Release After } \\
\text { Recharge }\end{array}$} \\
\hline lst & 7th & 15th & 16th & 23rd & 30th \\
\hline 1.062 & 0.860 & 0.281 & 0.668 & 0.568 & 0.504 \\
\hline
\end{tabular}

\section{INITIAL FLUORIDE RELEASE: -}

Comparing the three groups (GIC, RMGIC, CENTION) the maximum cumulative initial fluoride release was related to GIC(table 1) followed by RMGIC(table 2), CENTION(table 3). On comparison of 1 st, 7 th and 15 th day fluoride release, the fluoride release from all the materials was highest on lst day decreased gradually till the 7th day after that there was sharp decline in fluoride release from GIC and RMGIC, whereas for CENTION values remained almost constant over time.

\section{FLUORIDE RE RELEASE: -}

On recharging of different restorative materials, the fluoride re-release was high when $2 \% \mathrm{NaF}$ solution (professional regime)was used as compared to fluoridated dentifrice (Home regime). GIC had a greater recharge potential followed by RMGIC. CENTION had least recharge potential. In both the regimes fluoride re-release was greatest on the first day, decreased sharply till the 7th day after which the decrease was gradual.

\section{DISCUSSION: -}

Fluorides play a key role in the prevention and control of dental caries. There is no doubt that the discovery of the anticariogenic properties of fluoride was one of the most important landmarks in the history of dentistry ${ }^{1}$

Fluoride is well documented as an anti-cariogenic agent. The anti-cariogenic effects of fluoride involves a variety of mechanisms i.e, the enhancement of remineralization, the reduction of demineralization, the interference of pellicle and plaque formation and the inhibition of microbial growth and metabolism. Fluoride released from dental restorative materials is assumed to affect caries formation through all these mechanisms and may therefore reduce or prevent demineralization. ${ }^{2-3}$

Today, there are several fluoride-containing dental restoratives available in the market including GLASS-IONO MERS, RESIN MODIFIED GLASS-IONOMER CEM ENTS, POLYACID-MODIFIED COMPOSITES (COMP O MERS), COMPOSITES, CENTION. Due to their different matrices, set structure and setting mechanisms the products vary in their ability to release fluoride, and to promote remineralization of dental hard tissues.

The results of this current study agree with others that only GICs showed an initial fluoride burst effect. The first process is characterized by an initial burst of fluoride release from the surface after which the elution is markedly reduced, accompanied by the second bulk diffusion process by which small amounts of fluoride continue to be released into the surrounding media. This pattern of release has been observed in previous studies. In contrast to the Conventional and Resin modified glass ionomers, CENTION shown to have no initial fluoride burst effect but levels of fluoride release remain relatively constant over time.

On comparison of the amount of initial fluoride release, dental restoratives in descending order were conventional GIC, RMGIC, CENTION This is in accordance with the studies of Vermeersch, Leloup Vreven and Deniz C Can Karabulut et al. ${ }^{4}$ Two mechanisms have been proposed by which fluoride may be released from glass-Ionomers into an aqueous environment. One mechanism is a short-term reaction, which involves rapid dissolution from outer surface into solution (process I), whereas the second is more gradual and resulted in the sustained diffusion of ions through the bulk cement (process II) $^{5,6,7}$

An initial high release from glass-Ionomers over the first $24 \mathrm{~h}$ is likely due to the burst of fluoride released from the glass particles when reacting with the polyalkenoate acid during the setting reaction. ${ }^{12}$ Metal-reinforced glass-Ionomers seem to release less fluoride than conventional glass-Ionomer cements ${ }^{13}$ This effect may be explained by the initial lower fluoride content of these materials due to the replacement by silver or the formation of silver fluoride which binds the fluoride ions into the cement preventing leaching of the fluoride ${ }^{7}$

After application of fluoride regimes, the fluoride release from Conventional and Resin modified glass-ionomer cements could be increased and prolonged. The fluoride re-release was less for CENTION, that recharging ability of the glassionomer cements was superior to that of CENTION, Glassionomers are mostly found to have significantly better capability to act as a fluoride reservoir than resin-based materials and CENTION.

This fact can be explained by the loosely bound water and the solutes in the porosities in the glass-ionomer, which may be exchanged with an external medium by passive diffusion. ${ }^{14}$ The absorption and re-release of fluoride might be determined by the permeability of the material. Thus, a completely permeable substance could absorb the ions deep into its bulk, while a relatively impermeable material can only absorb fluoride into the immediate subsurface. ${ }^{8}$

This may be clinically important because glass-ionomer restorations may act as intraoral devices for the controlled slow release of fluoride at sites at risk for recurrent caries. Release of fluoride after topical application is dependent on the $\mathrm{pH}$, concentration, dose, duration and frequency of application. All the restorative materials could be recharged by both the agents used in the study but as seen in the study the recharge after $2 \% \mathrm{NaF}$ application was greater than toothpaste application suggesting professional topical fluorides could recharge the restoratives greater than home regime.

Professional topical fluoride applications usually contain $2 \%$ $\mathrm{NaF}$ (9000ppm F) whereas home regime; toothpaste contains (1000ppm F). ${ }^{9}$ Professionally applied fluoride treatment provides a 2.5 to 4 -fold increase in fluoride release from fluoride containing dental materials ${ }^{10}$. Sodium fluoride solution induce disintegration of the matrix regions around glass fillers leading to increased ability of the fluoride recharge ${ }^{6}$. Our study confirms the findings of Takahashi et al., who demonstrated that fluoride release by glass-ionomer materials increases with exposure to increased fluoride concentration $^{11}$. In a study conducted by Freedman and Diefendefer, it was concluded that home care fluoride exposures provided adequate measurable fluoride uptake and subsequently release in these materials, with a higher level for resin modified glass ionomers. ${ }^{8}$

Irrespective of the recharging agent used, all the restorative materials showed an increased amount of fluoride re-release on recharging on the lst day followed by rapid return to near exposure levels suggesting the fluoride release after exposure to topical fluoride represents only a washout of ions adsorbed to the surface, rather than an actual diffusion into the matrix.

\section{LIMITATIONS OF THE STUDY:}

Within the limitations of the study design (specimen size, storage media, etc.) definitive conclusion cannot be made 
and further in vivo investigations are needed to evaluate fluoride release after exposure to fluoride regime under the dynamic conditions of oral cavity.

The clinical significance of the released fluoride is yet to be fully confirmed. Many factors such as the site into which the fluoride diffuses and the rate of diffusion will influence its anti caries effectiveness. The ultimate goal of correlating fluoride release with actual caries reduction is an objective that can only be met by completing controlled clinical studies on materials with well characterized kinetics of fluoride release

\section{CONCLUSION:}

The initial Fluoride release was highest from Conventional GIC followed by Resin Modified GIC, CENTION. The Fluoride re-release was high when recharging with professional regime ( $2 \% \mathrm{NaF})$ as compared to home regime (Toothpaste). Conventional GIC had a greater recharging ability followed by Resin Modified GIC, CENTION.

\section{REFERENCES:}

1. KarantakisP,Helvatjoglou-AntoniadesM,Theodoridou-PahiniS, Papado gia nnis Y. Fluoride release from three glass ionomers, a compomer, and a com po site resin in water, artificial saliva, and lactic acid. Oper Dent.2000 JanFeb;25(1):20-5

2. Rølla G, Ekstrand J. Fluoride in oral fluids and dental plaque. In: Fejerskov O,Ekstrand I, Burt BA, editors. Fluoride in dentistry. Copenhagen: Munksgaard;1996. p. 215-29.

3. Ten Cate JM, Featherstone JDM. Physicochemical aspects of fluo ride-enamelinteractions. In: Fejerskov O, Ekstrand J, Burt BA, editors. Fluoride indentistry. Copenhagen: Munksgaard; 1996. p. 252-72.

4. Itota $\mathrm{T}$, Carrick TE, Yoshiyama M, McCabe JF. Fluoride release and recharge ingiomer, compomer and resin composite. Dent Mater. 2004;20:789-95.

5. Verbeeck RM, De Maeyer EA, Marks LA, De Moor RJ, De Witte AM,Trimpeneers LM. Fluoride release process of (resin-modified) glass-ionomercements versus (polyacid-modified) composite resins. Biomaterials. 1998 Aprl;19(6):509-19.

6. Lee SY, Dong DR, Huang HM, Shih YH. Fluoride ion diffusion from a glass-ionomer cement. Journal of oral rehabilitation. 2000 Jul 1;27(7):576-86.

7. el Mallakh BF, Sarkar NK. Fluoride release from glass-ionomer cements indeionized water and artificial saliva. Dent Mater. 1990 Apr;6(2):118-22.

8. Preston AJ, Higham SM, Agalamanyi EA, Mair LH. Fluoride recharge ofaesthetic dental materials. Journal of oral rehabilitation. $1999 \mathrm{Dec}$ 1;26(12):936-40.

9. Okuyama K, Murata Y, Patricia N.R. Pereira, et al. Fluoride release and uptakeby various dental materials after fluoride application. Am J Dent. 2006;19(2):123-27

10. Hicks J, Godoy FC, Donly $\mathrm{K}$, Flaitz C. Fluoride releasing restorative materials andsecondary caries. Dent Clin N Am. 2002;46:247-76.

11. Takahashi K, Emilson CG, Birkhed D. Fluoride release in vitro from various glassionomer cements and resin composites after exposure to NaF solution. DentMater. 1993;9:350-54.

12. Wiegand A, Buchalla W, Attin T Review on fluoride-releasing restorat I've materials-fluoride release and uptake characteristics, antibacterial activit yand influence on caries formation. Dent Mater J. 2007 Mar 31;23(3):343-62.

13. Williams JA, Billington RW, Pearson GJ. A long term study of fluoridemetalresin-release fromcontaining conventional andmodified glass-io nomerc ements. Journal of oral rehabilitation. 2001 Jan 1;28(1):41-7.

14. Xu X, Burgess JO. Compressive strength, fluoride release and recharge offluoride-releasing materials. Biomaterials. 2003 Jun 30;24(14):2451-61.

15. Ruchika Bansal, Tajinder BansalA Comparative Evaluation of theAmount of Fluoride Release and Re-Release after Recharging from AestheticRestorative Materials: An in vitro Study JCDR/2015/1 1926.6278 